\begin{tabular}{|c|c|}
\hline Title & Reaction kinetics for the production of methylene urea from synthetic human urine \\
\hline Author(s) & Kabore, Steve; Ito, Ryusei; Funamizu, Naoyuki \\
\hline Citation & $\begin{array}{l}\text { Journal of environmental chemical engineering, 4(2), 2510-2517 } \\
\text { https://doi.org/10.1016/j.jece.2016.04.028 }\end{array}$ \\
\hline Issue Date & $2016-06$ \\
\hline DOC URL & http:/hdl.handle.net/2115/70625 \\
\hline Rights & $\begin{array}{l}\text { (9 2016. This manuscript version is made available under the CC-BY-NC-ND } 4.0 \text { license } \\
\text { http://reativecommons.org/icenses/by-nc-nd/4.0/ }\end{array}$ \\
\hline Rights(URL) & http://creativecommons.org/icenses/by-nc-nd/4.0/ \\
\hline Type & article (author version) \\
\hline File Information & Reaction Kinetics_Steve_Kabore.pdf \\
\hline
\end{tabular}

Instructions for use 


\title{
Reaction kinetics for the production of methylene urea from synthetic human urine.
}

\author{
Steve KABORE*, Ryusei ITO**, Naoyuki FUNAMIZU** \\ * Laboratory on Engineering for sustainable sanitation, Graduate School of Engineering, \\ Hokkaido University, Kita 13 Nishi 8, Sapporo, Hokkaido, 060-8628 Japan \\ Rekobasteve@yahoo.fr \\ ** Laboratory on Engineering for sustainable sanitation, Faculty of Engineering, Hokkaido \\ University, Kita 13 Nishi 8, Sapporo, Hokkaido, 060-8628 Japan \\ ryuusei@eng.hokudai.ac.jp / Funamizu@eng.hokudai.ac.jp
}

\begin{abstract}
The production of methylene urea from human urine is an important contribution to the world demand of nitrogen fertilizer. In this study, a simplified reaction model was proposed. The kinetics parameters at room temperature were assessed and the reaction constants $k_{1}, k_{2}, k_{3}, k_{4}$ were evaluated and determined for the different parts of the proposed reaction model. The relationship between the Formaldehyde/Urea (F/U ratio) and the recovery of nitrogen was also evaluated based on the contribution of the by-products from the reaction. The optimum F/U condition to maximize the recovery of nitrogen was determined.
\end{abstract}

Keywords: Polymerization; Urea; Formaldehyde; Fertilizer.

\section{INTRODUCTION}

The world demand of nitrogen fertilizer is gradually increasing and will be about 116 million tons in 2020 (FAO, 2012). People daily discharge $12.5 \mathrm{~kg}$ of nitrogen with $90 \%$ of that amount coming from urine (Del Porto, 1999). The potential amount of nitrogen produced from the 7 billion people is about 30 million tons. This counts for $25 \%$ of the total demand in the world. Therefore, the reuse of urine could provide an alternative source of nitrogen fertilizer. The energy consumption necessary for producing conventional ammonia based fertilizers could also be reduced. However, the direct application of urine in agriculture faces problems that might be considered. Excessive urine application inhibits plant growth due to increasing soil electrical conductivity (EC) (Mnkeni etal., 2008). The urine contains 0.5 wt. \% of sodium chloride which could accumulate in the soil system. Ammonia evaporation may release bad odor for the people near the field and washout by rainwater may also occur (Galloway and Cowling, 2002). There is also the concern of crops contamination by pathogens contained in the urine bringing the long storage requirement period; At least 6 months at more than $20^{\circ} \mathrm{C}$ (Höglund et al., 2002).

On the other hand, slow release fertilizers made from slowly degradable materials that can control the release rate of the nutrient by their own biochemical degradation rate therefore reducing nutrients losses (Trenkel, 2010). However, the industrial process for the production of the commercial slow release fertilizer appears to be stringent. The production of methylene urea which is a nitrogen slow release fertilizer is performed in temperature range about $60-100^{\circ} \mathrm{C}$ (Nair and Francis, 1982; L.M. Phynes 1983). During the fabrication process, intermittent controlled $\mathrm{pH}$ conditions and addition of urea is 
also done (M. Dunky 1997). Ito et al. (2013) succeeded to produce solid particles of methylene urea from urine at room temperature $\left(25^{\circ} \mathrm{C}\right)$ at $\mathrm{pH} 1-5$. Formaldehyde reacted with the urea to give precipitate. The concentration of urea decreased with elapse of time at all $\mathrm{pH}$ values while the rate was high at low ones. The experiments were performed using both synthetic and real human urine. The elemental analysis of the precipitates showed that they were identical to the commercial methylene urea. The recovery rate was gradually increasing with the increase in the ratio of formaldehyde to urea $(\mathrm{F} / \mathrm{U})$. The maximum was obtained for the equimolar $\mathrm{F} / \mathrm{U}$, then decreased at higher F/U. Kabore et al. (2015) studied the reaction occurring in the human urine. They found that it was different from the one used to produce the methylene urea available on the market. Indeed, in the case of human urine sub reactions leading to by-products have to be considered. They therefore proposed a reaction model that considers the main reaction path leading to the recovery of methylene urea and also secondary paths leading to the related by-products.

To design a reactor to produce the slow released fertilizer from human urine, the kinetics constants of the reaction have to be determined. Basically, those constants are necessary to compute the reaction rates $(r)$, the volume $(V)$ and the residence time $(\tau)$. In realistic situation, the design includes a series of reactors with recirculation of the species. In such cases, the kinetics parameters are necessary to also compute the periodical concentrations of the different species.

The objectives of this research paper were (1) to evaluate the kinetics parameters for the proposed mathematical model of the reaction, (2) to perform a simulation with the mathematical model for obtaining quantitative data and for designing the reactor, (3) to analyze the contribution of the soluble products on the recovery of nitrogen and therefore determining the optimum $\mathrm{F} / \mathrm{U}$ ratio condition for the highest recovery of nitrogen.

\section{MATERIALS AND METHODS}

\section{Preparation of samples}

Synthetic urine solution whose composition is summarized in table 1 was used to simulate real urine (Wilsenach et al., 2007). Two hundred millilitres of the synthetic urine was taken in a tightly closed glass bottle during the reaction to avoid escape of gases. The $\mathrm{pH}$ was adjusted to 2 with concentrated hydrochloric acid solution (JIS special grade, Wako Pure Chemical Industries). This specific value of $\mathrm{pH}$ was used based on the effect on the reaction rate described by Ito (2013). It was also based on the large capacity of the acidic condition to avoid the hydrolysis of urea in the urine during storage and experiments (Hellstrom et al., 1998; Hotta and Funamizu 2008). The reaction temperature was kept at $25{ }^{\circ} \mathrm{C}$ in a water bath. A specific volume of $36 \%$ formaldehyde solution (JIS special grade, Wako Pure Chemical Industries) was added to the solution to start the reaction with mixing by a magnetic stirrer. The ratio of $\mathrm{F} / \mathrm{U}$ in 
the solution for each experiment is summarized in table 2. The solution was periodically taken during 24 hours, and then filtrated with glass fibre filter (GB 140, Advantec). The $\mathrm{pH}$ of the filtrates was adjusted to 7 with $1 \mathrm{~mol} / \mathrm{L}$ sodium hydroxide (JIS special grade, Wako Pure Chemical Industries) solution to slow the reaction.

Table 1 Composition of synthetic urine

\begin{tabular}{ccc}
\cline { 2 - 3 } & \multicolumn{2}{c}{ Concentrations } \\
\hline Components & $\mathrm{g} / \mathrm{L}$ & $\mathrm{mmol} / \mathrm{L}$ \\
\hline $\mathrm{MgCl} 2 \cdot 6 \mathrm{H}_{2} \mathrm{O}$ & 0.65 & 3.20 \\
$\mathrm{NaCl}$ & 4.60 & 78.70 \\
$\mathrm{Na}_{2} \mathrm{SO}_{4}$ & 2.30 & 16.20 \\
$\mathrm{Na}_{3}\left(\mathrm{C}_{6} \mathrm{H}_{5} \mathrm{O}_{7}\right) \cdot 2 \mathrm{H}_{2} \mathrm{O}$ & 0.76 & 2.60 \\
$\mathrm{KCl}$ & 1.60 & 21.50 \\
$\mathrm{C}_{4} \mathrm{H}_{7} \mathrm{~N}_{3} \mathrm{O}$ & 1.10 & 9.70 \\
$\mathrm{CaCl}_{2} \cdot 2 \mathrm{H}_{2} \mathrm{O}$ & 0.65 & 4.40 \\
$\mathrm{KH}_{2} \mathrm{PO}_{4}$ & 4.20 & 30.90 \\
$\mathrm{NH}_{4} \mathrm{Cl}$ & 1.00 & 18.70 \\
$\left(\mathrm{NH}_{2}\right)_{2} \mathrm{CO}$ & 25.03 & 416 \\
$\mathrm{Na}_{2}(\mathrm{COO})_{2}$ & 0.02 & 0.15 \\
$\mathrm{C}_{6} \mathrm{H}_{8} \mathrm{O}_{6}$ & 0.10 & 0.57 \\
\hline
\end{tabular}

Table 2 Amount of formaldehyde and corresponding ratio to urea.

\begin{tabular}{ccc}
\hline $\begin{array}{c}\text { Volume of urine } \\
(\mathrm{mL})\end{array}$ & F/U ratio & $\begin{array}{c}\text { Volume of } \\
\text { formaldehyde } \\
(\mathrm{mL})\end{array}$ \\
\hline \multirow{2}{*}{200} & 0.5 & 3.48 \\
& 1 & 6.95 \\
& 2 & 13.9 \\
\hline
\end{tabular}

\section{Measurements in liquid phase}

The urea concentration, the total nitrogen (TN) and the formaldehyde concentration were respectively measured with a LC-MS system (LC system 626 with Shodex RSpak DE-413 column, Waters), a TN meter (TOC-VCSH, Shimadzu, Kyoto Japan) and formaldehyde measurement agents (MBTH method 8110) with a spectrophotometer (DR-2800, Hach). The total organic carbon (TOC) was measured using a liquid 
chromatography with organic carbon detection (LC-OCD, chromatograph for organics in water, model 8, DOC-LABOR DR. HUBER).

\section{Measurements in solid phase}

Solid residues on the filters were dried at $105^{\circ} \mathrm{C}$ for 24 hours and weighted with an electric balance. The concentration of nitrogen and carbon in the solid phase was measured with a CN coder (Sumigraph NC-220F, Sumika Chemical Analysis Service).

\section{Simulation and computing}

The original mathematical model of the reaction proposed by Kabore et al. (2015) considers the reactants of urea and formaldehyde ( $U$ and $F$ ), solid products of methylene-urea ((UF) $)_{3}$ ), intermediate polymers (UF and (UF) $)_{2}$ ), and by-products (FUF, UFU, UFUFU and UFUFUFU). However, the simplified model, as shown in Figure 1, was adopted because the concentration of the intermediates and by-products cannot be accurately measured. So, the reactants $U$ and F, the solid products of $(U F)_{3}$, the intermediate UF, and the by-products of FUF and UFU are considered.

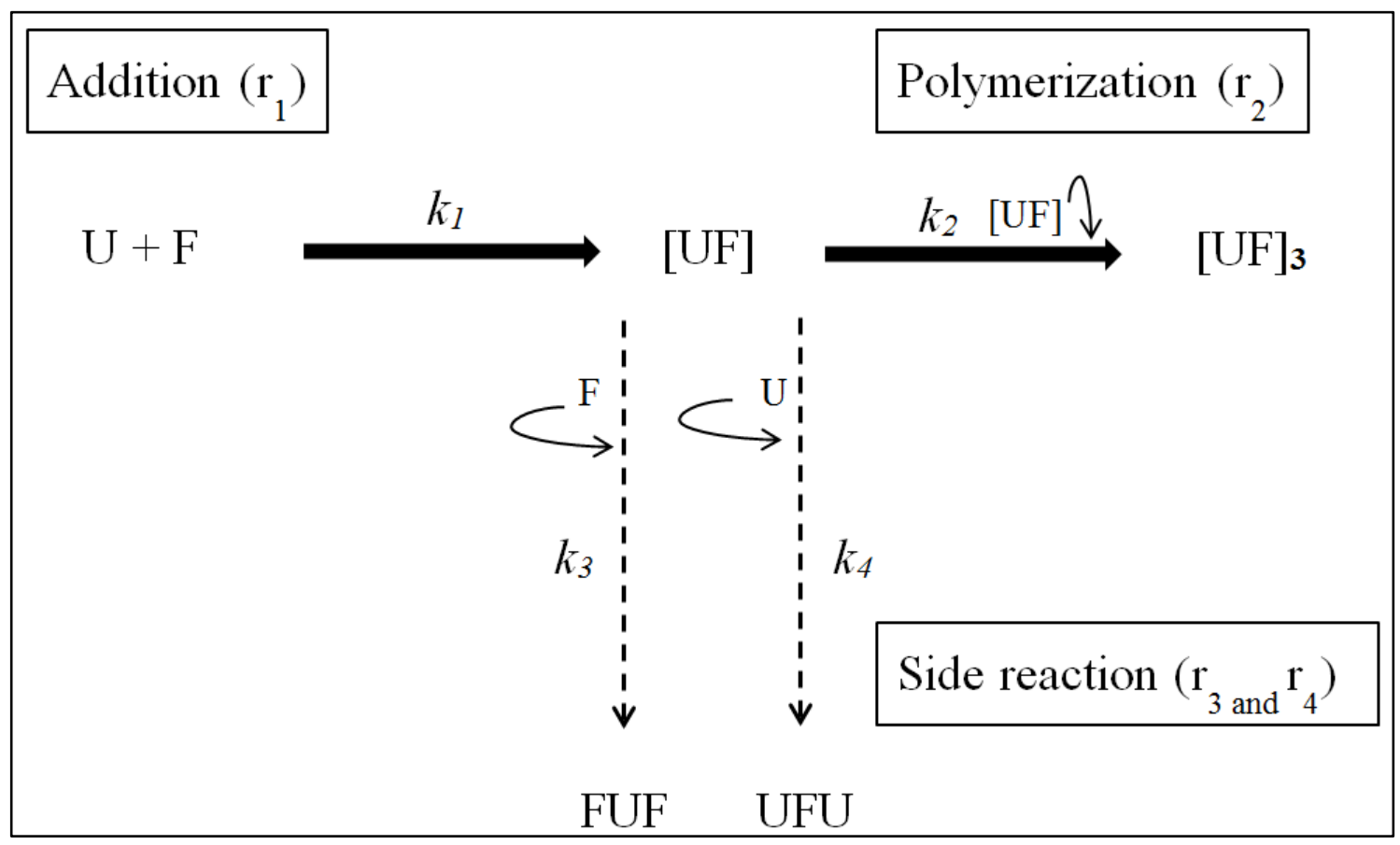

Figure 1 Simplified reaction model 
The soluble products concentration which is the sum of intermediate and by-products in the experimental data can be estimated from the mass balances of carbon and nitrogen as respectively described in equations (1) and (2):

$$
\begin{aligned}
& \text { Soluble products }_{\text {exp,C }}=\text { TOC }-[\mathrm{U}]_{\mathrm{C}}-[\mathrm{F}]_{\mathrm{C}} \\
& \text { Soluble products } \mathrm{exp}, \mathrm{N}=\mathrm{TN}-[\mathrm{U}]_{\mathrm{N}}-[\mathrm{F}]_{\mathrm{N}}
\end{aligned}
$$

where, $[\mathrm{U}]_{\mathrm{C}},[\mathrm{U}]_{\mathrm{N}},[\mathrm{F}]_{\mathrm{C}}$ and $[\mathrm{F}]_{\mathrm{N}}$ are respectively carbon and nitrogen concentrations of $U$ and F. Regarding the simulated data, the soluble product concentration is defined as the sum of UF, FUF and UFU in equations (3) and (4) respectively for carbon and nitrogen content:

$$
\begin{aligned}
& \text { Soluble products }_{\text {sim, }}=[\mathrm{UF}]_{\mathrm{C}}+[\mathrm{FUF}]_{\mathrm{C}}+[\mathrm{UFU}]_{\mathrm{C}} \\
& \text { Soluble products }_{\mathrm{Sim}, \mathrm{N}}=[\mathrm{UF}]_{\mathrm{N}}+[\mathrm{FUF}]_{\mathrm{N}}+[\mathrm{UFU}]_{\mathrm{N}}
\end{aligned}
$$

With, $[\mathrm{UF}]_{\mathrm{C}},[\mathrm{UF}]_{\mathrm{N}},[\mathrm{FUF}]_{\mathrm{C}},[\mathrm{FUF}]_{\mathrm{N}},[\mathrm{UFU}]_{\mathrm{C}}$ and $[\mathrm{UFU}]_{\mathrm{N}}$ are respectively the carbon and nitrogen concentrations of UF, FUF and UFU. The conversion factors were introduced to calculate the carbon and nitrogen content from molar concentrations of components based on their molecular structures as shown in table 3 . The equations related to the elementary rate laws and the reaction rates are collected in table 4 . These equations were computed with the Runge Kunta method. The least square method on the area difference between simulated and experimental data was applied for optimization of the reaction coefficients. 
Table 3 Conversion factors to carbon and nitrogen content

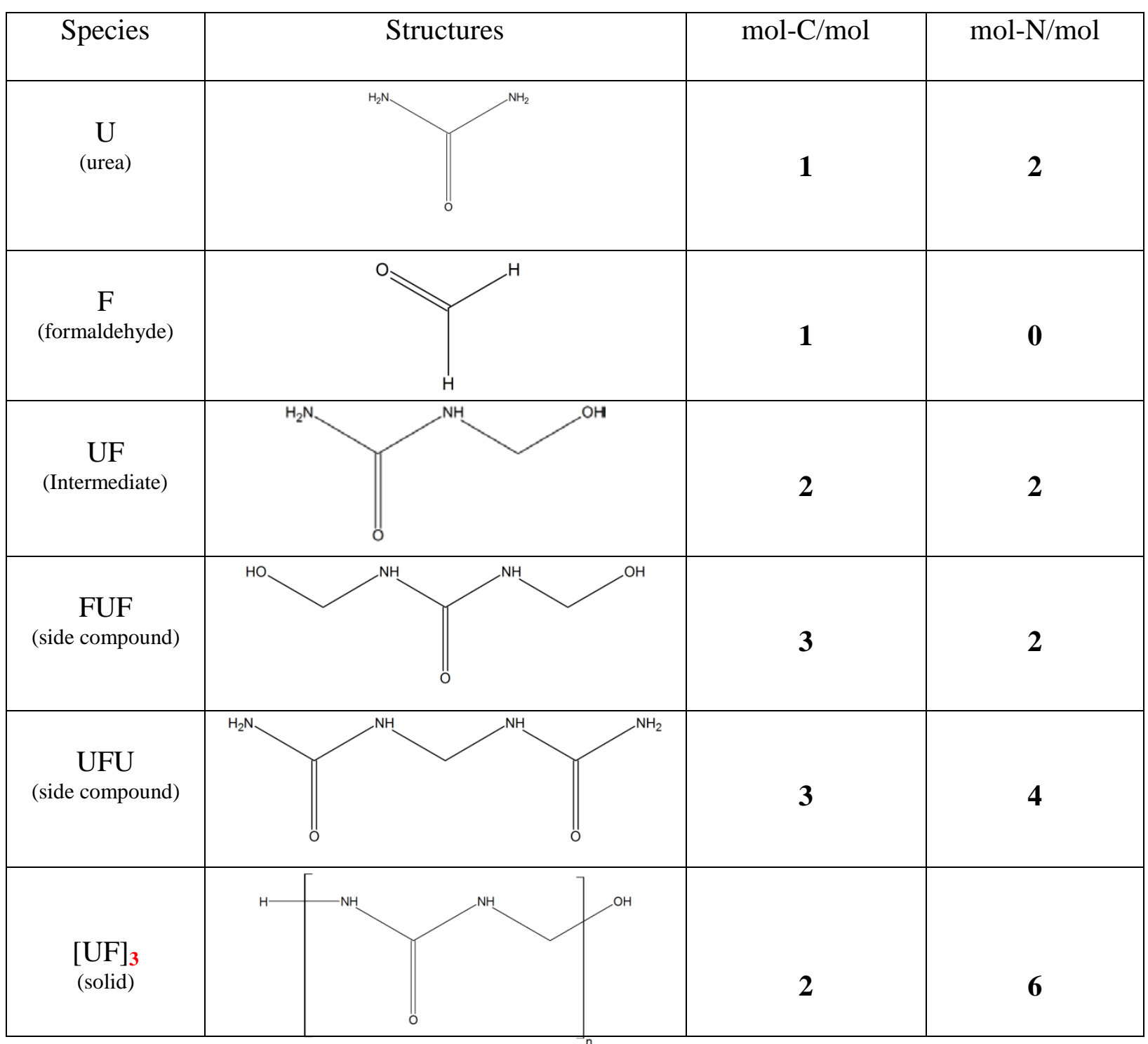


Table 4 Simulated equations

\begin{tabular}{|c|l|}
\hline \multicolumn{1}{|c|}{ Species } & Elementary rate laws \\
\hline $\begin{array}{c}\mathrm{U} \\
\text { (urea) }\end{array}$ & $\frac{\mathrm{d}[\mathrm{U}]}{\mathrm{dt}}=-k_{1}[\mathrm{U}][\mathrm{F}]-k_{4}[\mathrm{UF}][\mathrm{U}]$ \\
\hline $\begin{array}{c}\mathrm{F} \\
\text { (formaldehyde) }\end{array}$ & $\frac{\mathrm{d}[\mathrm{F}]}{\mathrm{dt}}=-k_{1}[\mathrm{U}][\mathrm{F}]-k_{3}[\mathrm{~F}] \quad[\mathrm{UF}]$ \\
\hline $\begin{array}{c}\mathrm{UF} \\
\text { (Intermediate) }\end{array}$ & $\frac{\mathrm{d}[\mathrm{UF}]}{\mathrm{dt}}=-k_{1}[\mathrm{U}][\mathrm{F}]-3 k_{2}[\mathrm{UF}]^{3}-k_{3}[\mathrm{~F}] \quad[\mathrm{UF}] \quad-k_{4}[\mathrm{U}] \quad[\mathrm{UF}]$ \\
\hline $\begin{array}{c}{[\mathrm{UF}]_{3}} \\
\text { (solid) }\end{array}$ & $\frac{\mathrm{d}[\mathrm{UF}]_{3}}{\mathrm{dt}}=k_{2}[\mathrm{UF}]^{3}$ \\
\hline $\begin{array}{c}\mathrm{FUF} \\
\text { (side compound) }\end{array}$ & $\frac{\mathrm{d}[\mathrm{FUF}]}{\mathrm{dt}}=-k_{3}[\mathrm{~F}] \quad[\mathrm{UF}]$ \\
\hline $\begin{array}{c}\mathrm{UFU} \\
\text { (side compound) }\end{array}$ & $\frac{\mathrm{d}[\mathrm{UFU}]}{\mathrm{dt}}=k_{4}[\mathrm{U}][\mathrm{UF}]$ \\
\hline Rate $\mathrm{r}_{1}$ & $\mathrm{r}_{1}=k_{1}[\mathrm{U}][\mathrm{F}]$ \\
\hline Rate $\mathrm{r}_{2}$ & $\mathrm{r}_{2}=k_{2}[\mathrm{UF}]^{3}$ \\
\hline Rate $\mathrm{r}_{3}$ & $\mathrm{r}_{3}=k_{3}[\mathrm{~F}][\mathrm{UF}]$ \\
\hline Rate $\mathrm{r}_{4}$ & $\mathrm{r}_{4}=k_{4}[\mathrm{U}][\mathrm{UF}]$ \\
\hline
\end{tabular}

\section{Experiment in real human urine}

The data of the experiment performed by Ito et al., using real human urine have been collected to evaluate the precision of the model for real case. In that experiment, the $\mathrm{F} / \mathrm{U}$ ratio was about 0.5 and the reaction time set to $24 \mathrm{~h}$. The kinetics parameters of our model were then applied to those original data. The time course of urea concentration was observed. 


\section{RESULTS AND DISCUSSION}

\section{Experimental data}

Figures 2(a) and (b) respectively illustrate the time courses of carbon and nitrogen concentrations of the species for $\mathrm{F} / \mathrm{U}=1$. The dots represent the experimental data. The carbon and nitrogen concentration of $U$ and carbon concentration of $F$ decreased with time to indicate that they were just consumed to produce intermediates. The nitrogen concentration of $\mathrm{F}$ does not appear because formaldehyde structure is free from this element. The concentrations of soluble products increased then decreased, but they did not reach 0 . This fact suggests a rapid production and consumption of the intermediate at first stage while the remaining soluble products may contain by-products which do not produce precipitates. The concentrations of solid products increased with time. The recovery rate of nitrogen as the solid products for $\mathrm{F} / \mathrm{U}=1$ was $85 \%$ after 24 hours.

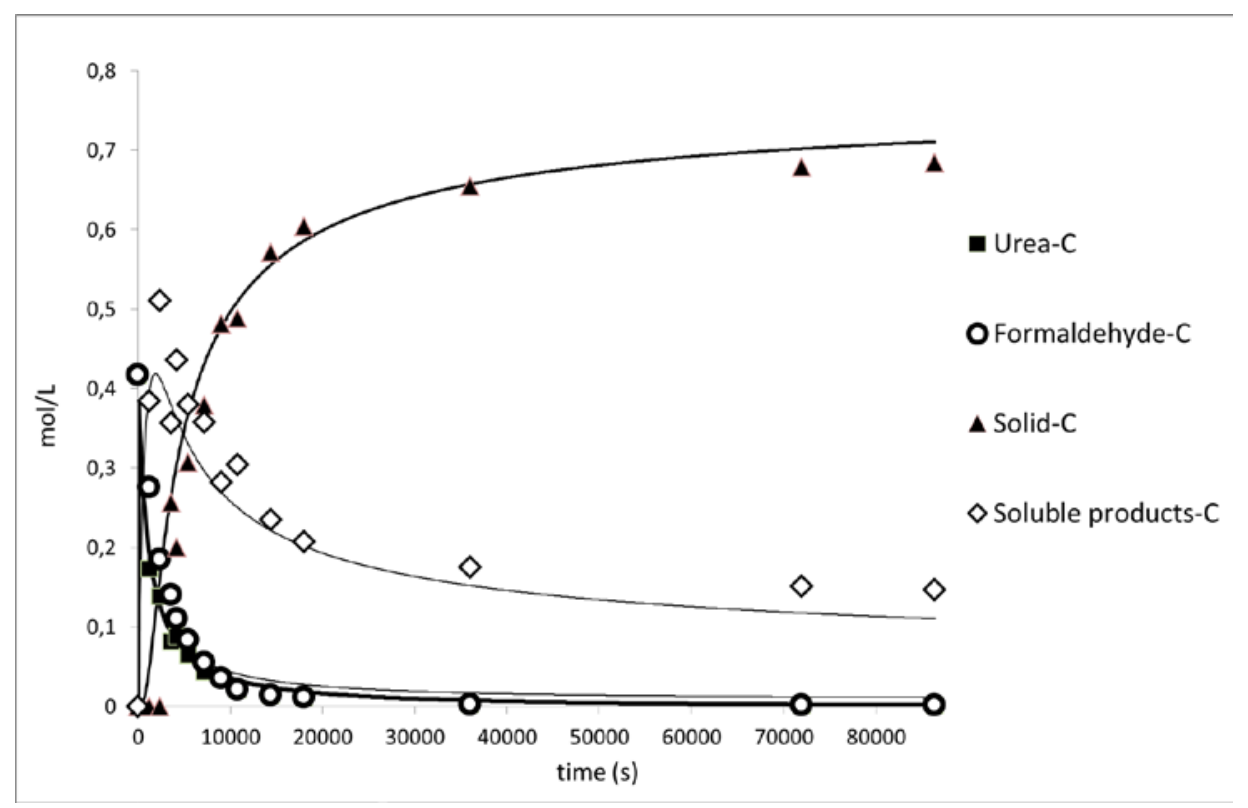

Figure 2(a) Time course of carbon of the different species for $F / U=1$ 


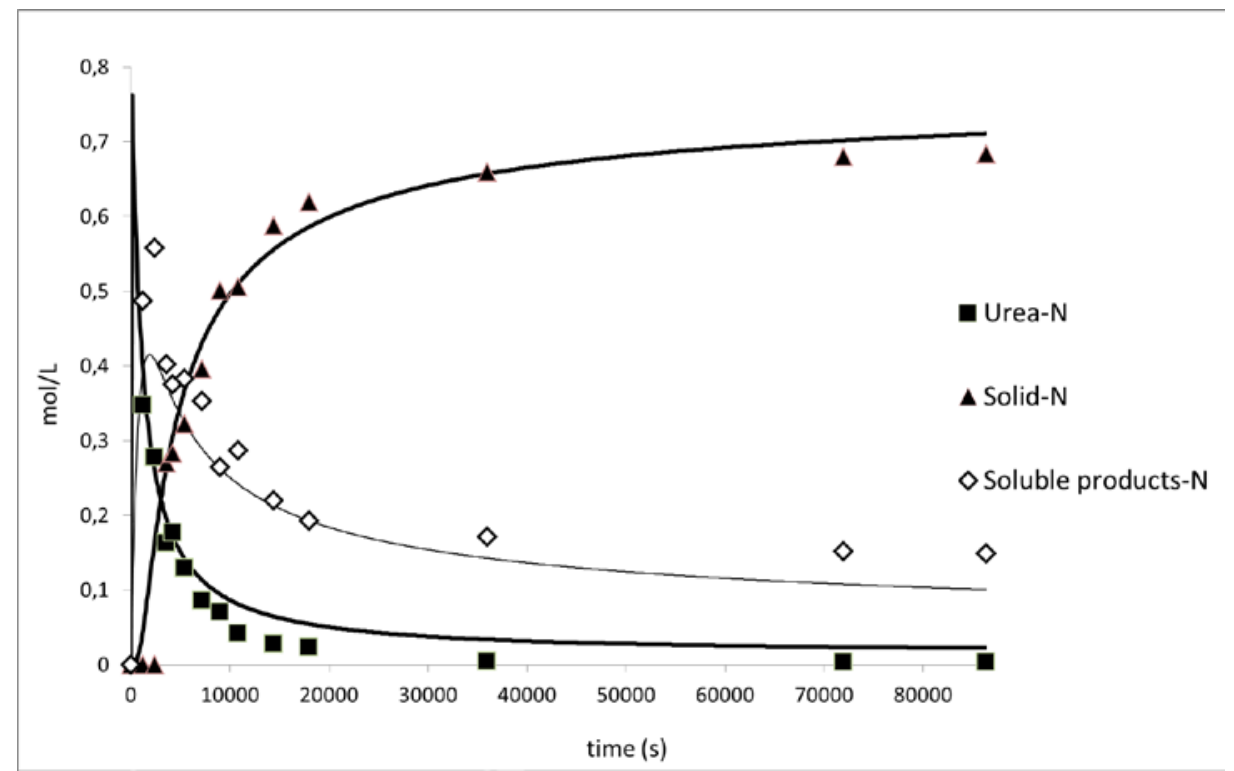

Figure 2(b) Time course of nitrogen of the different species for $F / U=1$

Figures 3(a) and (b) respectively show the carbon and nitrogen concentrations for $\mathrm{F} / \mathrm{U}=2$. The concentrations gave same trends as $\mathrm{F} / \mathrm{U}=1$, but the excess $\mathrm{F}$ was observed at final stage of the reaction. The recovery rate of nitrogen, $70 \%$, was lower than $F / U=1$, although most of $U$ was consumed in the reaction. This also indicates the existence of by-products. Figure 4(a) and (b) respectively show the carbon and nitrogen concentrations for $\mathrm{F} / \mathrm{U}=0.5$. These figures also give same trend on the concentrations. The $\mathrm{U}$ remains after 24 hours, although the $\mathrm{F}$ was almost consumed. The nitrogen recovery was $50 \%$.

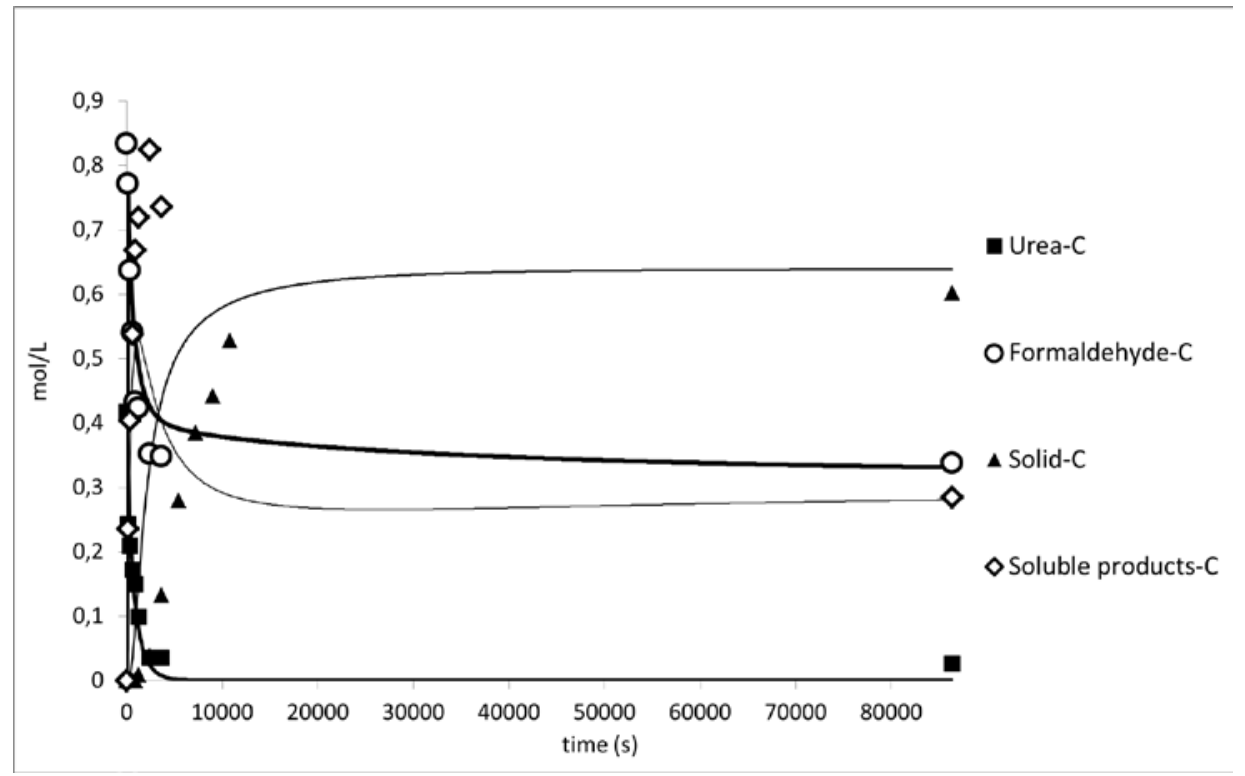

Figure 3(a) Time course of carbon of the different species for $F / U=2$ 


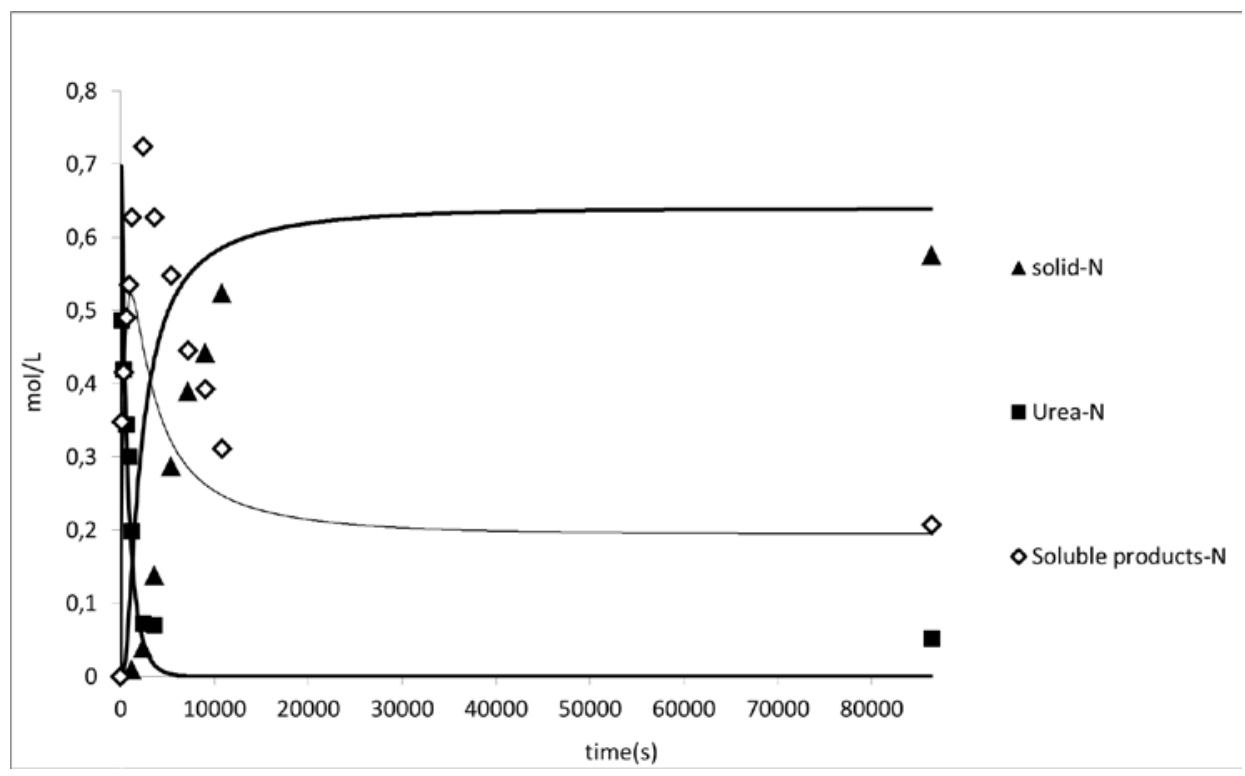

Figure 3(b) Time course of nitrogen of the different species for $F / U=2$

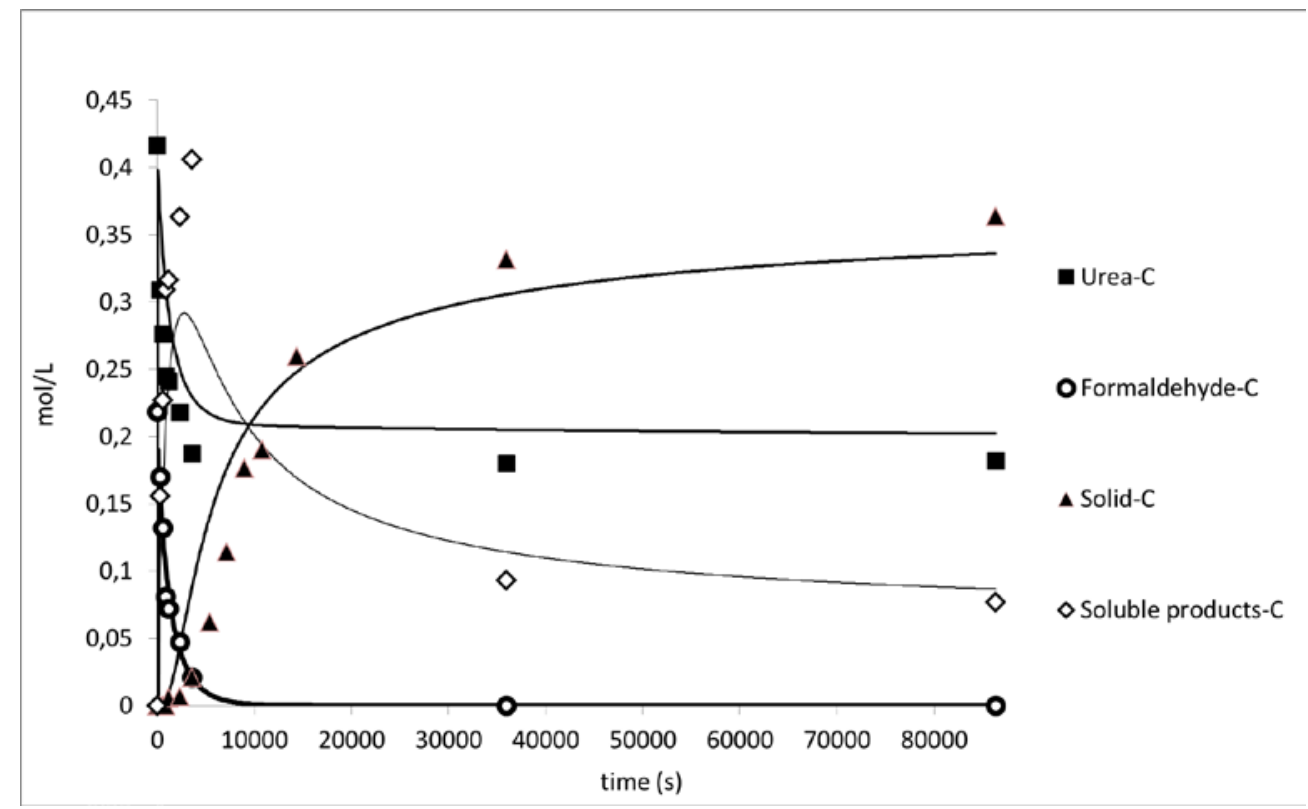

Figure 4(a) Time course of carbon of the different species for $F / U=0.5$ 


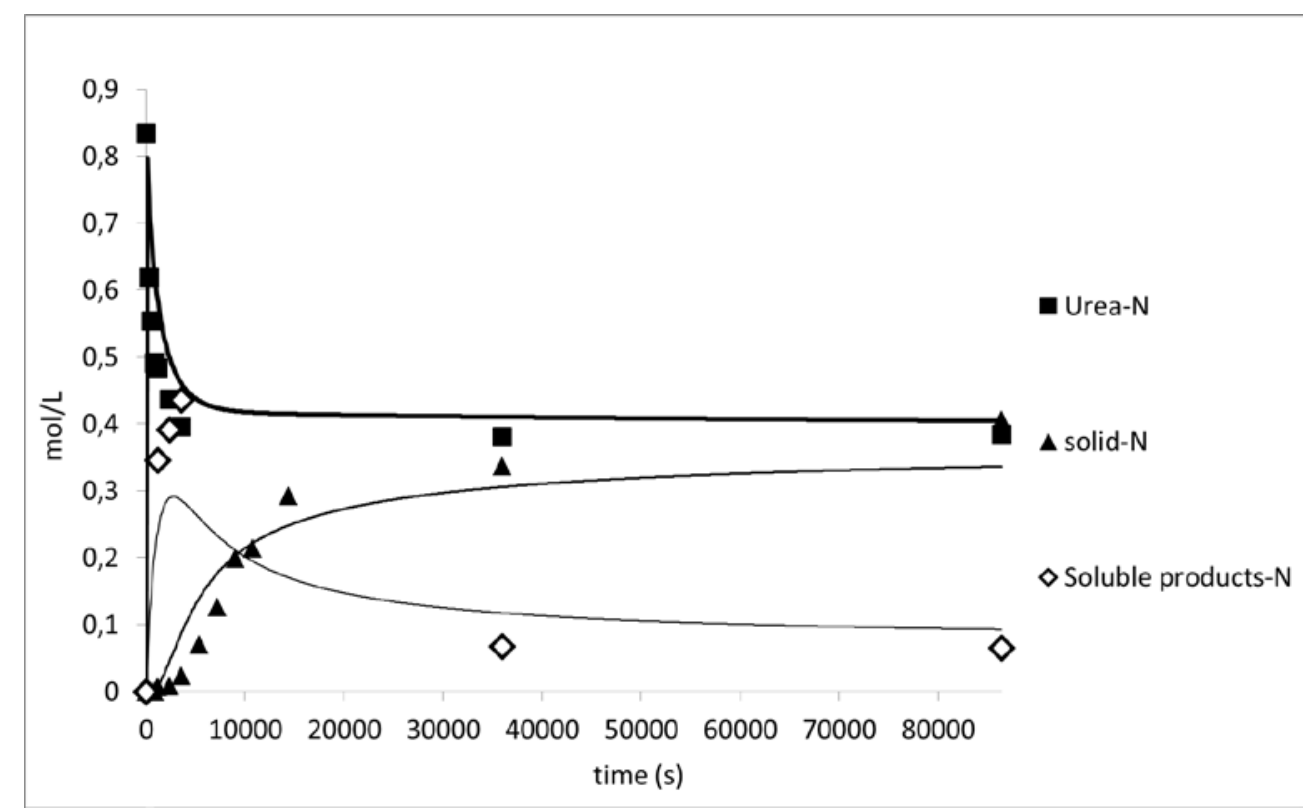

Figure 4(b) Time course of nitrogen of the different species for $F / U=0.5$

\section{Application of the mathematical model}

The mathematical simulation with the simplified reaction model was performed to find the optimized reaction constants using the data of $F / U=1$. The solid lines in the figures 2-4 show the simulation results. The obtained reaction constants were $k_{1}=2.24 \times 10^{-3} \quad\left(\mathrm{~L}^{-1} \cdot \mathrm{mol}^{-1} \cdot \mathrm{s}^{-1}\right), \quad k_{2}=2.05 \times 10^{-3} \quad\left(\mathrm{~L}^{-2} \cdot \mathrm{mol}^{-2} \cdot \mathrm{s}^{-1}\right), \quad k_{3}=5.96 \times$ $10^{-5}\left(\mathrm{~L}^{-1} \cdot \mathrm{mol}^{-1} \cdot \mathrm{s}^{-1}\right)$ and $k_{4}=8.13 \times 10^{-6}\left(\mathrm{~L}^{-1} \cdot \mathrm{mol}^{-1} \cdot \mathrm{s}^{-1}\right)$. The simulation results also showed good fit for $\mathrm{F} / \mathrm{U}=2$ and 0.5 . To maximize the recovery rate of nitrogen as solid particles, minimizing the concentration of soluble products is necessary. Figures 5(a)-(c) respectively illustrate composition of soluble products for $F / U=1,2$ and 0.5 . The reaction time was extended to 10 days to check whether the equilibrium of those soluble products was reached. At equimolar condition, a very rapid increase and decrease of intermediate UF was observed. Slight increase of the by-product UFU was found with higher concentration than FUF. This is due to the fact that the reaction rate coefficient to produce UFU is larger than that of FUF. When the F concentration was higher than $U$ like $\mathrm{F} / \mathrm{U}=2$ condition, the rapid increase of UF followed by its complete consumption was similarly observed. But in contrast, the concentration of FUF was greater than UFU, because the high concentration of $\mathrm{F}$ gave higher production rate of FUF comparing to the one of UFU. At excessive $U$ condition as $F / U=0.5$, the trends were similar to equimolar condition. 


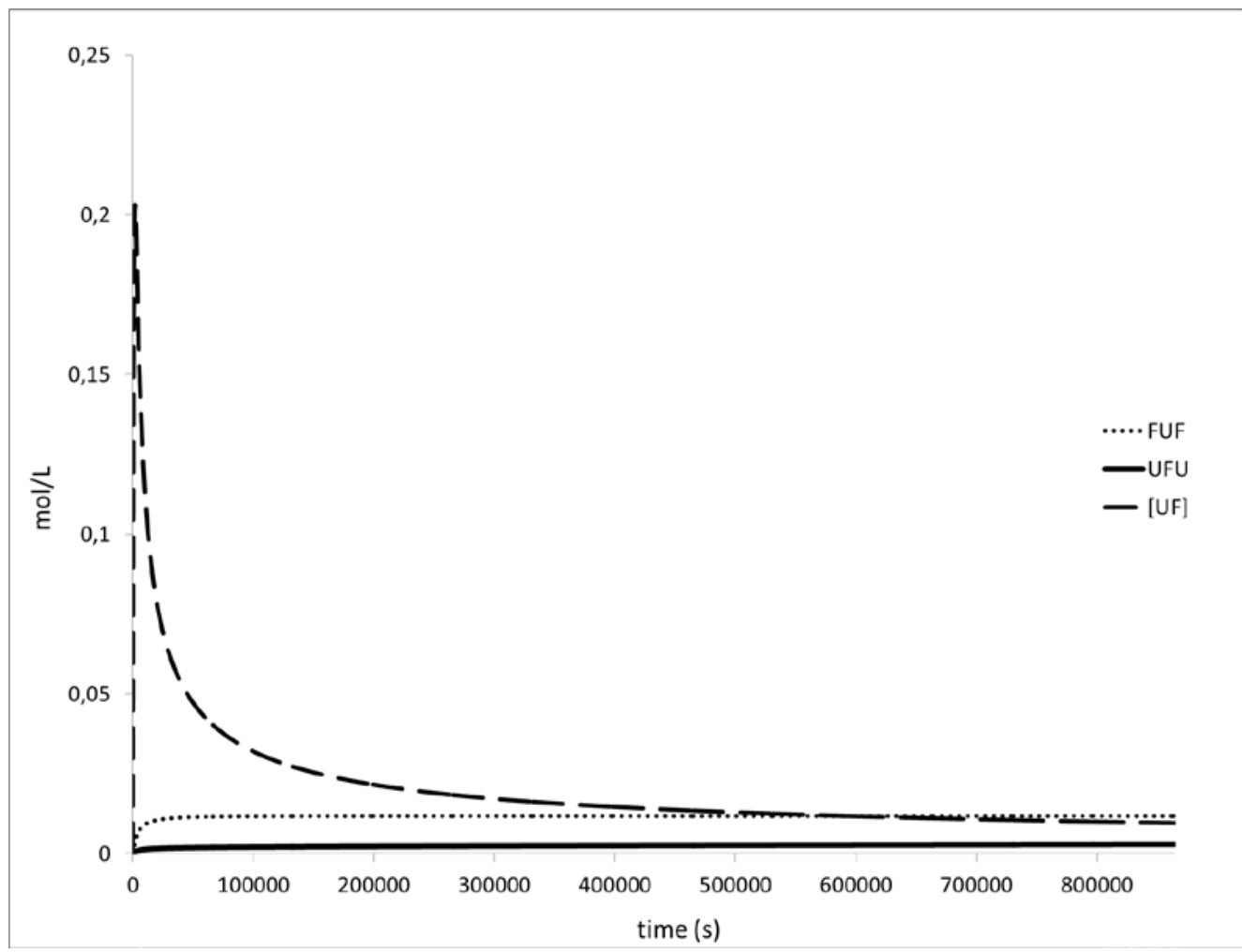

Figure 5(a) Contribution of FUF, UFU and [UF] for 10 days reaction time $\mathbf{F} / \mathrm{U}=1$

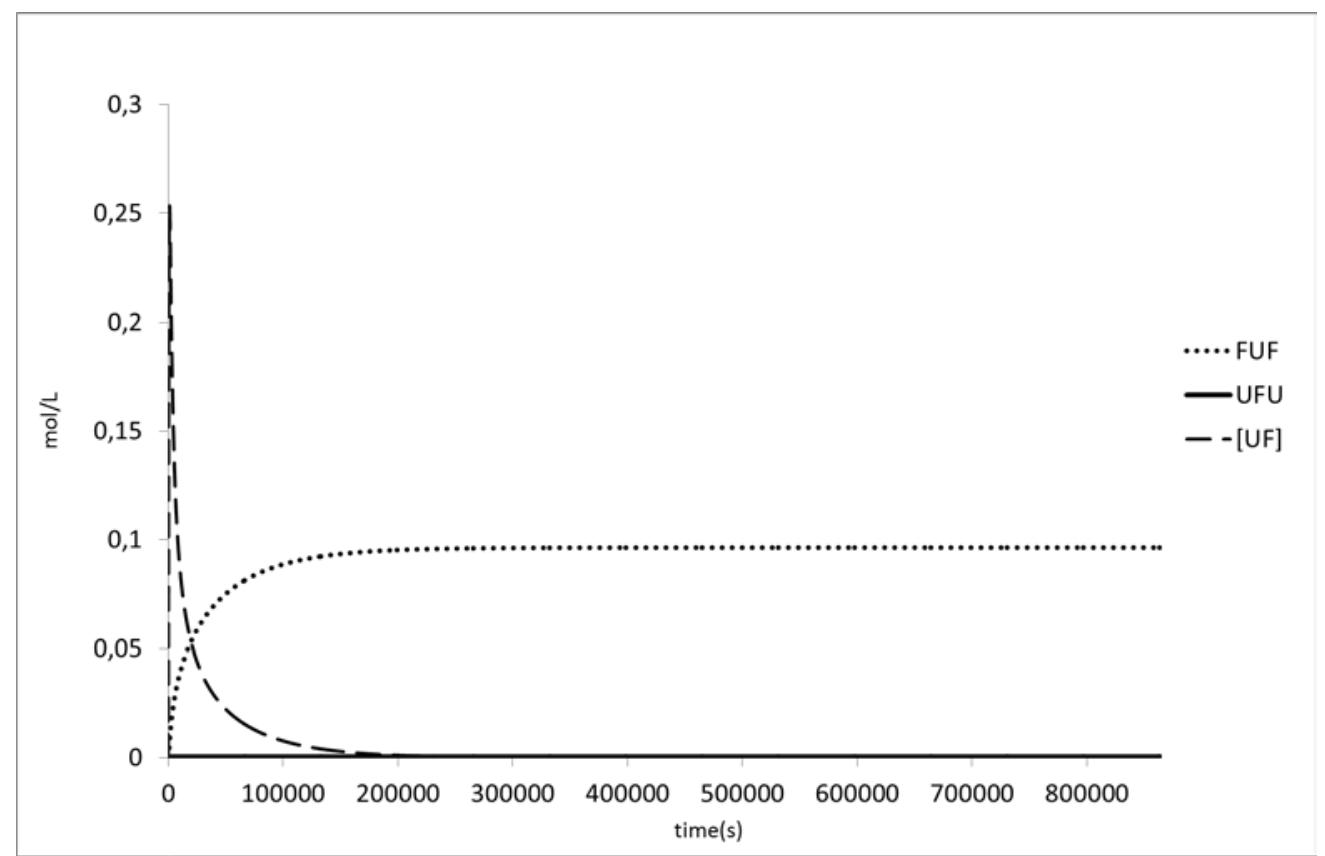

Figure 5(b) Contribution of FUF, UFU and [UF] for 10 days reaction time $\mathrm{F} / \mathrm{U}=\mathbf{2}$ 


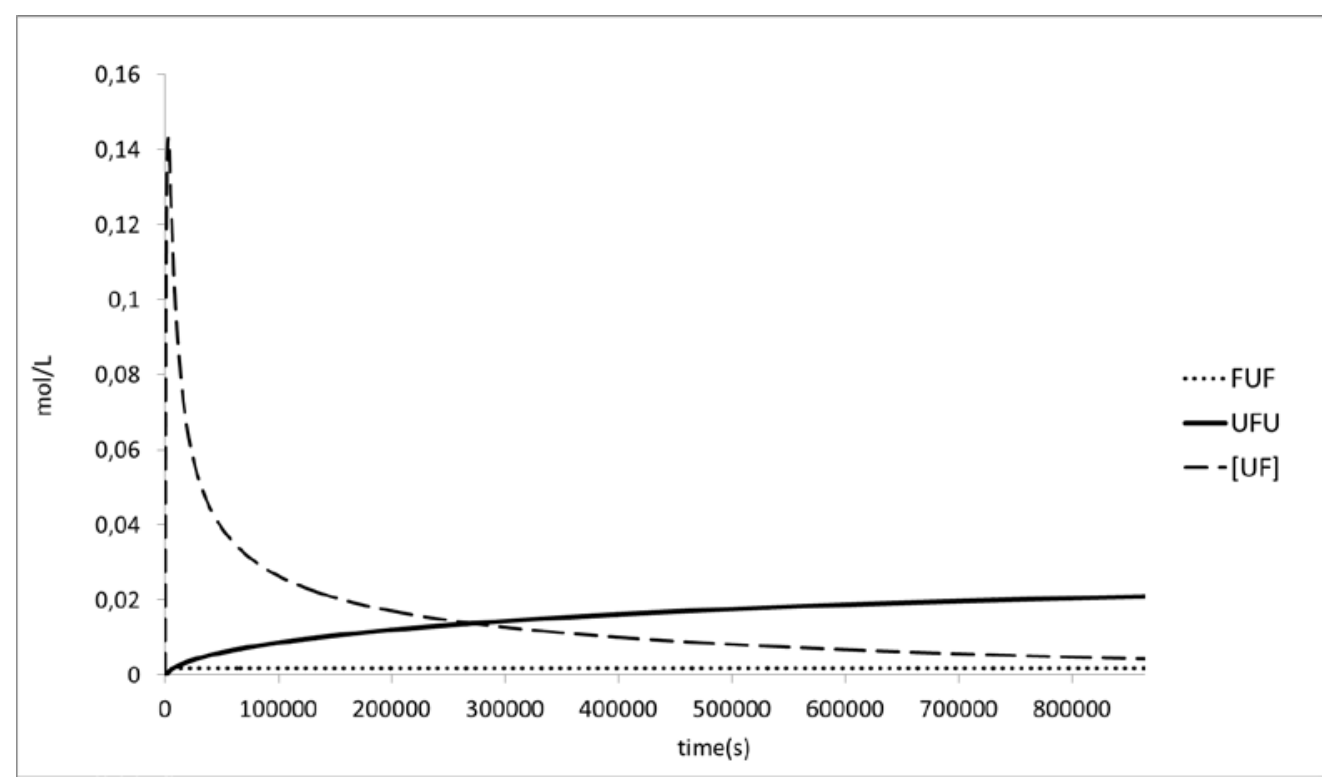

Figure 5(c) Contribution of FUF, UFU and [UF] for 10 days reaction time $\mathbf{F} / \mathbf{U}=\mathbf{0 . 5}$

Figure 6 shows the relation of the F/U ratio to the recovery at 24 hours of reaction. The recovery pattern is based on the three experimental ratios $(F / U=1,2$ and 0.5$)$ while the solid line is from simulated F/U ratios. Nitrogen recovery was gradually increasing with the addition of formaldehyde until the highest recovery at $F / U=1.2$. When the $F / U$ was higher than the peak, the recovery decreased with increase in F/U because of formation of FUF as discussed previously. So, the F/U should be controlled around 1 to maximize the nitrogen recovery. 


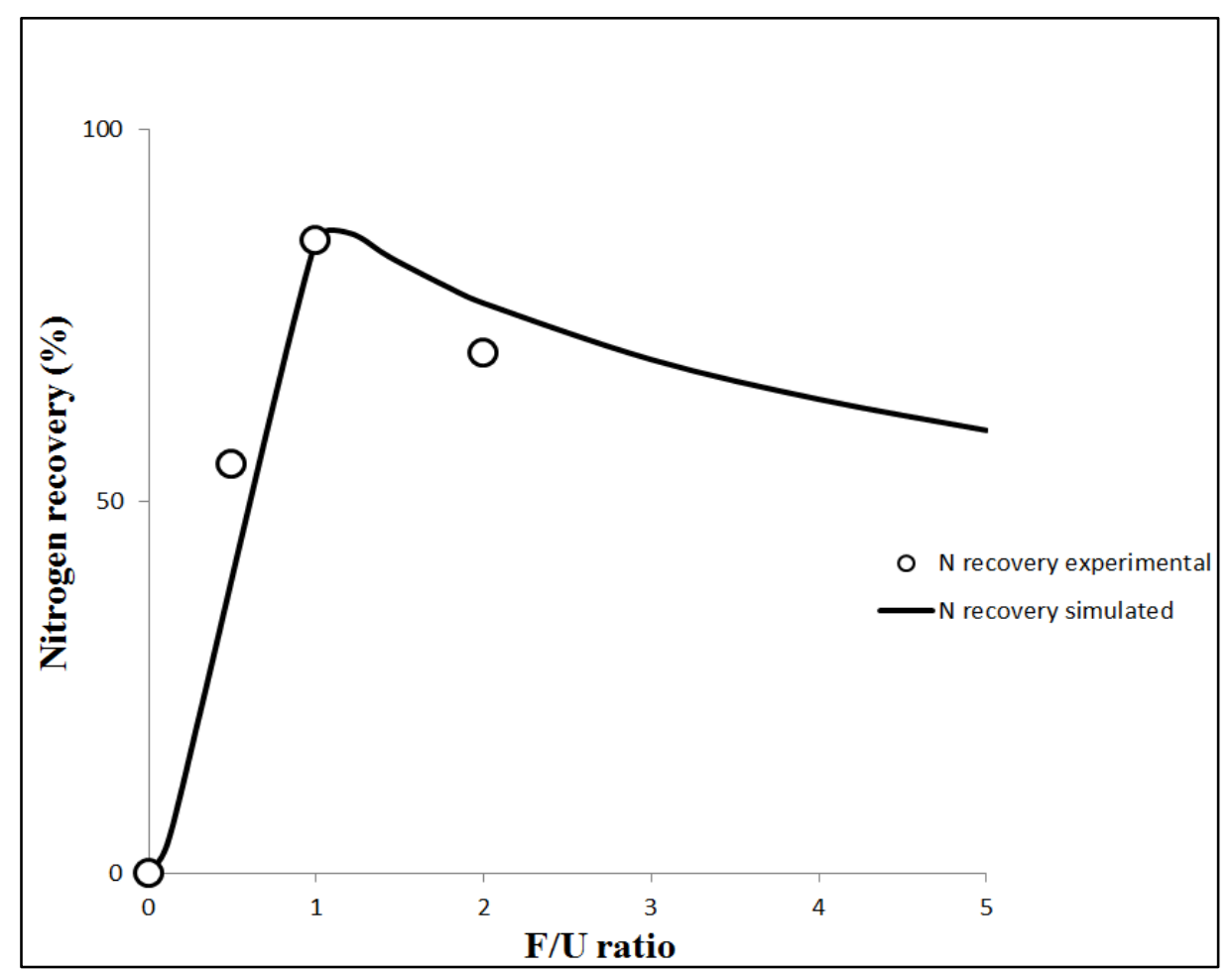

Figure 6 Recovery of nitrogen at equilibrium based on the F/U ratio

\section{Experiment in real human urine}

Figure 7 is the consumption of urea in real human urine. During the first stage which is the addition reaction with formaldehyde, the concentration of urea rapidly decreased and then reached the equilibrium. The behaviour of urea is essential as it is the one converted into slow release fertilizer throughout the reaction. The experimental and simulated data are shown for Urea-C and Urea-N respectively in Figure 7(a) and (b). As expected, the model was applicable with good fitting using the kinetics constants determined in this study. 


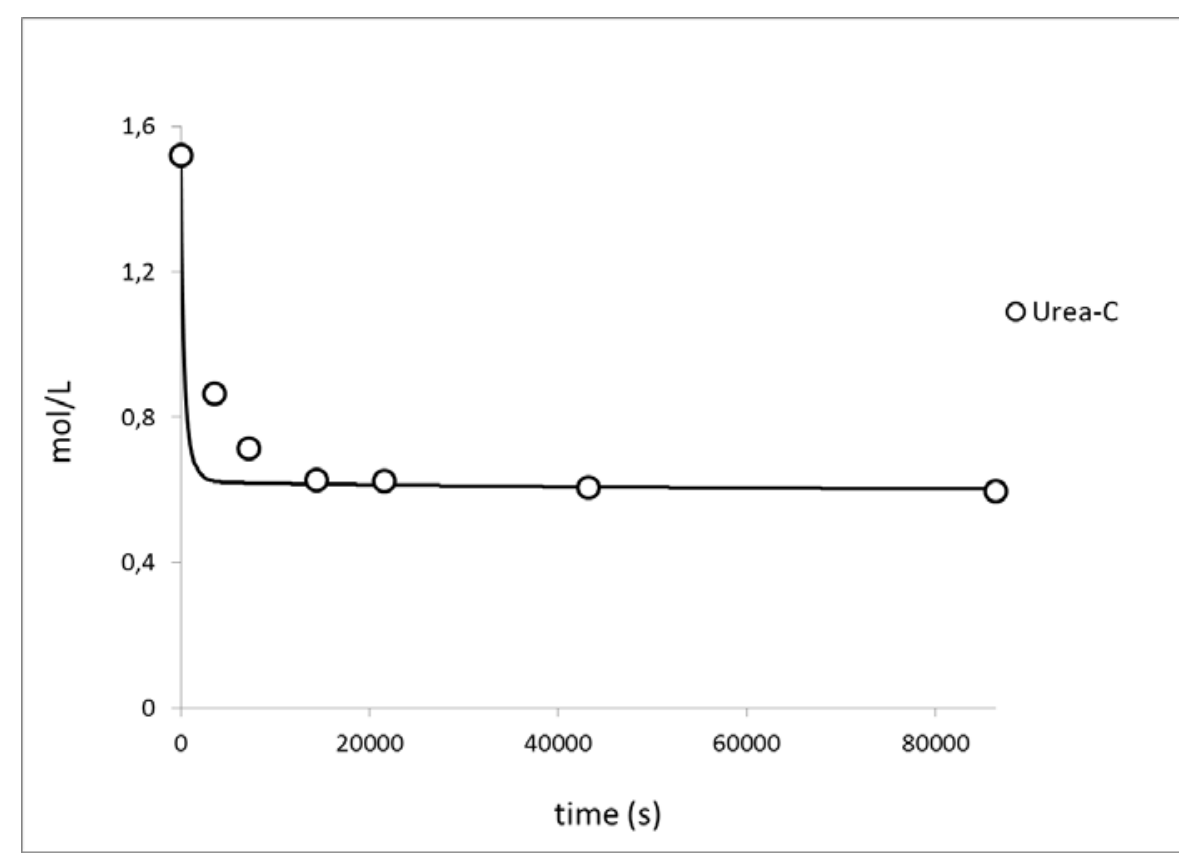

Figure 7(a) Application of the model to real human urine (Urea-C)

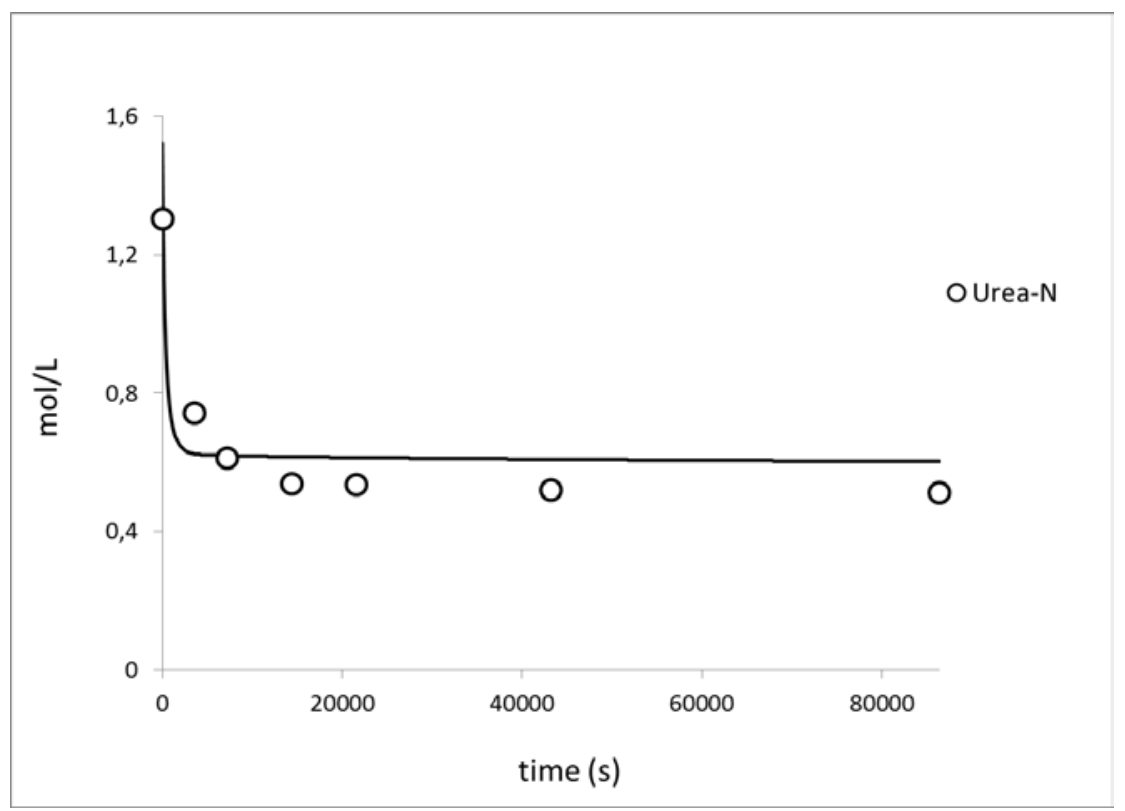

Figure 7(b) Application of the model to real human urine (Urea-N)

\section{Conclusion}

The kinetics for the production of methylene urea from human urine was investigated in this study. A simplified reaction model was proposed and the reaction constants at $25^{\circ} \mathrm{C}$ were determined for the different parts of the reaction. Constants $k_{1}=2,24.10^{-3}$ for the addition reaction of urea and formaldehyde to produce the monomer [UF]; $k_{2}=2,05.10^{-3}$ 
for the polymerization process leading to the precipitate; $k_{3}=5,96.10^{-5}$ for the side reaction that forms the soluble product FUF and $k_{4}=8,13.10^{-6}$ for the side reaction that forms the soluble product UFU. The model also fitted and described the cases of low and high load of formaldehyde. Side reaction leading to UFU was predominant for the first one while the other side reaction forming FUF was predominant for the latter. The optimum $\mathrm{F} / \mathrm{U}$ ratio condition for the highest recovery of nitrogen must be set up to 1.2 at $\mathrm{pH} 2$ and at room temperature $\left(\approx 25^{\circ} \mathrm{C}\right)$.

The current findings in the reaction kinetics allow the design of the reactor regarding the calculation of the volume, the reaction rates and the determination of the residence time. Future perspective may focus on further minimization of the by-products during the production through a system of reactors.

\section{References}

Del Porto D, Steinfeld C, 1999. The Composting Toilet System Book: A Practical Guide to Choosing, Planning and Maintaining Composting Toilet Systems, a Water-saving, Pollution-preventing Alternative

FAO (2009) FAOSTAT. Food and Agriculture Organization of the United Nations, Rome, Italy, http://faostat3.fao.org/browse/R/RF/E. (Accessed 5th September 2015).

Galloway J.N. and Cowling E.B. (2002) Reactive nitrogen and the world: 200 years of change. Ambio 31(2), 64-71.

Hellstrom D., Johansson E., Grennberg K. (1999) Storage of human urine: acidification as a method to inhibit decomposition of urea. Ecological Engineering 12, 253-269

Hotta S., Funamizu N. (2006) Evolution of ammoniacal potential in storage process of urine with fecal contamination. Bioresource Technology. 99 (13-17)

Höglund, C., Ashbolt, N. and Stenström, T. A.2002. Microbial risk assessment of source-separated urine used in agriculture. Waste Management and Research 20:162-171.

Ito R., Takahashi E., Funamizu N. (2013) Production of slow-released nitrogen fertilizer from urine. Environmental Technology. 34 (2809-2815) 
Kabore S., Ito R., Funamizu N., (2015). Effect of urea/formaldehyde ratio on the production process of methylene urea from human urine. Journal of Water and Environmental Technology (Accepted Nov. 2015)

Mnkeni P.N.S., Kutu F.R., Muchaonyerwa P. (2008). Evaluation of human urine as a source of nutrients for selected vegetables and maize under tunnel house conditions in the Eastern Cape, South Africa. Waste Management and Res., 26: 132-139.

Trenkel M.E. (2010) Slow- and Controlled-Release and Stabilized Fertilizers: An Option for Enhancing Nutrient Efficiency in Agriculture Second edition. International Fertilizer Industry Association, Paris, France.

Wilsenach J. A., C. A. H. Schuurbiers, and M. C. M. van Loosdrecht (2007) Phosphate and potassium recovery from source separated urine through struvite precipitation. Water research 41 (2007). pp. 458-66. 